\title{
A 0-D MODEL TO PREDICT THE RELATIONSHIP BETWEEN RESISTANCE AND COMPLIANCE IN PULMONARY ARTERIAL HYPERTENSION
}

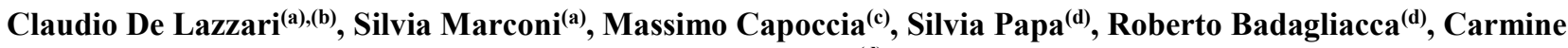 \\ Dario Vizza ${ }^{(d)}$
}

\author{
(a) National Research Council, Institute of Clinical Physiology (IFC-CNR), Rome, Italy \\ (b) National Institute for Cardiovascular Research (I.N.R.C.), Bologna, Italy \\ ${ }^{(c)}$ Royal Brompton Hospital, Royal Brompton \& Harefield NHS Foundation Trust, London, UK \\ (d)Department of Cardiovascular Respiratory Nephrologic and Geriatric Sciences, Sapienza University of Rome, Italy \\ (a),(b) $\underline{\text { claudio.delazzari@ifc.cnr.it, }}{ }^{(a)} \underline{\text { silvia.marconi@ifc.cnr.it, }}{ }^{(\mathrm{c})}$ capoccia@doctors.org.uk, ${ }^{(\mathrm{d})}$ silvia.papa@uniroma1.it, \\ (d) roberto.badagliacca@uniroma1.it, ${ }^{(\mathrm{d})}$ dario.vizza@uniroma1.it
}

\begin{abstract}
The inverse relationship between pulmonary vascular resistance and arterial compliance plays a significant role for the treatment of pulmonary arterial hypertension. The hyperbolic relationship between pulmonary vascular resistance and arterial compliance enables to evaluate the percentage of resistance reduction, which ultimately leads to an improvement in compliance. The numerical representation of the pulmonary circulation can help clinicians evaluate these key parameters in relation to therapeutic intervention. In this paper, we present a 0 -D numerical model of the pulmonary circulation. The right ventricular pressure is reproduced using a modified time-varying elastance and the pulmonary bed is modelled with RLC elements.

Preliminary results obtained from clinical parameters measured in patients with pulmonary arterial hypertension are discussed in this context. The simulations performed using the 0 -D model have been applied to a clinical setting to evaluate the percentage change induced on compliance by a reduction in resistance in fixed circulatory conditions.
\end{abstract}

Keywords: time-varying elastance, numerical model, pulmonary arterial hypertension, pulmonary compliance

\section{INTRODUCTION}

The inverse relationship between pulmonary vascular resistance $(P V R)$ and arterial compliance $(P V C)$ plays a significant role for the treatment of pulmonary arterial hypertension (PAH). Different causes may lead to PAH (Barst 2004) but all of them increase right ventricular (RV) afterload.

Two different analyses provide important information to understand the effects of pharmacological treatment in patients affected by PAH. The first one is the PVRPVCtime (RC-time) analysis in which resistance and compliance are related by an inverse hyperbolic function. In this analysis, it must be kept in mind that the RC-time can be influenced by the pulmonary capillary wedge pressure $(P C W P)$. The second one is based on the right ventricular pulmonary arterial coupling defined as the ratio between the pulmonary arterial elastance $\left(E_{a}\right)$ and the slope $\left(E_{e s}\right)$ of the EndSystolic Pressure-Volume Relationship (ESPVR) of the right ventricle. For the left ventricle, a normally coupled cardiovascular system is characterized by $E_{a} / E_{e s}$ values between 0.5 and 1.5 (Guarracino 2013). A normal value for right ventricular-pulmonary arterial coupling is $E_{e s} / E_{a}>1.5$ (Kuehne 2004, Tello 2019). The optimal mechanical coupling occurs when the ratio is 1.0. Numerical models of the right circulation may help understand the mechanism of pulmonary arterial hypertension in relation to diagnosis, treatment and prognosis (Lankhaar 2006). CARDIOSIM ${ }^{\odot}$ software simulator of the cardiovascular system may well be an appropriate tool to address some of the issues related to pulmonary arterial hypertension (De Lazzari 1998, 2009 , 2010). In this work we have assembled CARDIOSIM $^{\odot}$ with two pressure generators for the right atrial pressure and $P A C W P$. The right ventricular pressure was simulated with a modified time-varying elastance model. The pulmonary circulation was represented with three different sections: main pulmonary artery, small pulmonary artery and pulmonary arteriole and capillary compartments (De Lazzari 2019).

Preliminary results have been obtained from clinical parameters measured in patients affected by PAH.

\section{MATERIALS AND METHODS}

CARDIOSIM $^{\odot}$ is the software package of the cardiovascular simulator developed in the Institute of Clinical Physiology (Rome Section) of the National Research Council (De Lazzari 2011). The software is interactive and capable of reproducing physiological and pathological conditions for clinical decision-making in a controlled environment. This simulation software platform has seven modules: left and right heart (composed by ventricles and atria), systemic and pulmonary arterial sections, systemic and pulmonary venous sections and coronary circulation. Different 
lumped parameter (0-D) models with variable degree of complexity levels have been implemented for each module. All modules are stored in the CARDIOSIM ${ }^{\odot}$ library where numerical models of different mechanical circulatory assist devices (MCADs) are also available, which can reproduce the behavior of:

* pneumatic left, right and biventricular assist devices (LVAD, RVAD and BVAD) (De Lazzari 1998);

* intra-arterial, axial-flow pump such as Hemopump (LVAD, RVAD and BVAD) (De Lazzari 2006);

* PUlsatile Catheter Pump (PUCA pump) (Fresiello 2011);

* IntraAortic Balloon Pump (IABP) (De Lazzari 2001, Marconi 2018);

* Berlin Heart INCOR pump (Capoccia 2018);

* biventricular pacemaker (De Lazzari 2013);

* Thoracic Artificial Lung (TAL) (De Lazzari 2014).

Two different modules have been implemented in CARDIOSIM $^{\odot}$ library to reproduce the native heart behavior. In the first one the ventricles, the atria and the septum have been modelled according to the timevarying elastance theory (De Lazzari 2017) with the aim to reproduce the inter-ventricular (IVS) and the interatrial (IAS) septum behavior and the intra-ventricular or inter-ventricular conduction delays. In the second one, described below, the filling and ejection phases of the ventricle are modelled separately using the time-varying elastance concept (De Lazzari 2005).

In CARDIOSIM $^{\odot}$ the different modules can be assembled according to the need of the simulation with the aim to reproduce physiological and pathological conditions, which can be treated with drugs, MCADs or both. In addition, the effects induced by mechanical ventilation can be simulated during MCADs assistance (De Lazzari 1998, 2001, 2006, 2013, 2014).

Fig. 1 shows the model of the pulmonary circulation assembled and used for this study.

\subsection{Electrical analogue of the pulmonary circulation} The right atrial pressure (Pra) and the pulmonary capillary wedge pressure (Wedge) are modelled with two fixed pressure generators, which can be manually changed throughout the cardiac cycle during the simulations.

The behavior of the main (small) pulmonary artery section is reproduced with a 0 -D numerical model implemented using resistance $R_{\text {pam }}\left(R_{\text {pas }}\right)$, inertance $L_{\text {pam }}$ $\left(L_{p a s}\right)$ and compliance $C_{p a m}\left(C_{p a s}\right) . R_{p a c}, L_{p a c}$ and $C_{p a c}$ reproduce the pulmonary arteriole and capillary section. The tricuspid valve is modelled with two resistances $\left(R_{r i}\right.$ and $R_{i n v}$ ) and one diode. $R_{i n v}$ allows the simulation of tricuspid regurgitation. The valve between the right ventricle and the pulmonary bed is modelled with a resistance $\left(R_{r o}\right)$ and a diode.

The variable resistance $R_{a p}$ enables to reproduce the effects of the peripheral pulmonary resistance.

\subsection{Right ventricle}

Within CARDIOSIM ${ }^{\odot}$ library, a numerical model reproducing the filling and ejection phases of the right ventricle separately was selected.

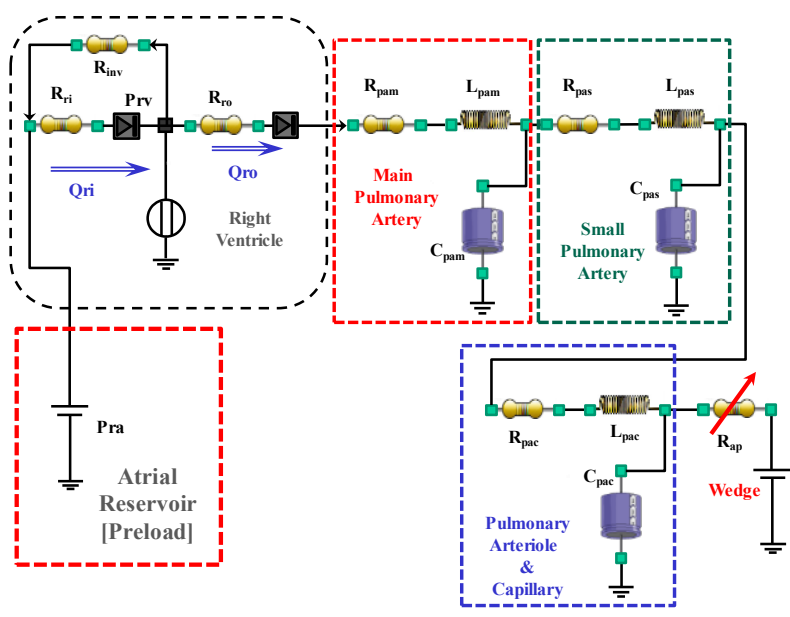

Figure 1: Electrical Analogue of the Pulmonary Circulation.

The contraction and ejection phase can be simulated with the modified time-varying elastance model according to the following equation (De Lazzari 2005):

$$
\operatorname{Prv}(t)=\left[\operatorname{Vrv}(t)-\operatorname{Vrv} v_{0}\right] \cdot \operatorname{Erv}(t) \cdot\left(1+a \cdot \frac{d V r v(t)}{d t}\right)
$$

$\operatorname{Prv}(t)$ is the instantaneous right ventricular pressure, $\operatorname{Vrv}(t)$ is the instantaneous right ventricular volume, $\operatorname{Erv}(t)$ is the right ventricular elastance, $a$ is a constant and $V r v_{0}$ is the resting right ventricular volume.

The right ventricular filling phase is reproduced by:

$$
\operatorname{Prv}(t)=C \cdot e^{k \cdot V r v(t)}+D \cdot e^{-j \cdot V r v(t)}+E
$$

The constants $C, D, E, k$ and $j$ reproduce the right ventricular filling properties. $C$ and $k$ modify the right ventricular rigidity. $D$ and $j$ change the right ventricular aspiration phase. $E, k$ and $j$ vary the resting right ventricular volume $\left(V r v_{0}\right)$. Eq. (2) describes the EndDiastolic Pressure-Volume Relationship (EDPVR) curve in the pressure-volume (P-V) plane (Fig. 2).

Different EDPVR curves are obtained by changing the values of $C, D, E, k$ and $j$ (see the box in Fig. 2). In the $\mathrm{P}-\mathrm{V}$ plane, Eqs. (1) and (2) describe the ventricular loop, the ESPVR and the EDPVR.

In Fig. $2 E_{a}$ is the arterial elastance and $E_{e s}$ is the ventricular elastance. The ratio between these two variables is the expression of ventricular coupling.

This numerical ventricular representation reproduces Starling's law of the heart. 


\subsection{Patient description}

The software simulator reproduced the patient's basal conditions. The clinically measured parameters are listed in Table 1. The trans-pulmonary gradient (TPG), defined, as the difference between $P A P$ and $P C W P$, is $47 \mathrm{mmHg}$, which is well above the cut-off of $12 \mathrm{mmHg}$ making this patient completely unsuitable for heart transplant. Although attractive, a combined heart and lung transplant is not widely performed, donor availability is more limited and controversy remains.

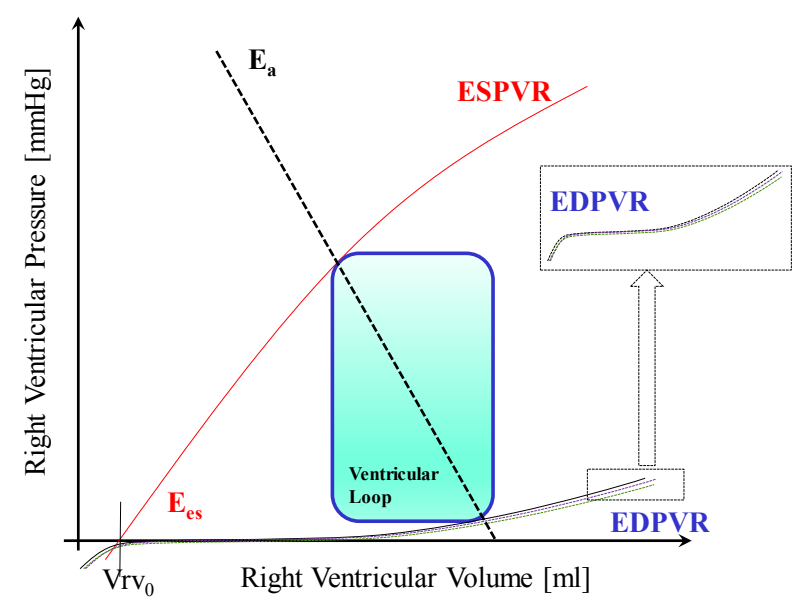

Figure 2: Right Ventricular Loop in the PressureVolume Plane.

Table 1: Basal Conditions

\begin{tabular}{|c|c|}
\hline NYHA & II-III \\
\hline Heart Rate $(H R)[\mathrm{bpm}]$ & 70 \\
\hline Body Surface Area $(B S A)\left[\mathrm{m}^{2}\right]$ & 1.97 \\
\hline Right Atrial Pressure $(P r a)[\mathrm{mmH}]$ & 4.0 \\
\hline $\begin{array}{c}\text { Mean Pulmonary Arterial Pressure }(P A P) \\
{[\mathrm{mmHg}]}\end{array}$ & 58.0 \\
\hline Mean $P C W P[\mathrm{mmHg}]$ & 11.0 \\
\hline Cardiac Output $(\mathrm{CO})\left[1 \cdot \mathrm{min}^{-1}\right]$ & 5.8 \\
\hline Cardiac Index $(C I)\left[1 \cdot \mathrm{min}^{-1} \cdot \mathrm{m}^{-2}\right]$ & 2.94 \\
\hline Total Pulmonary Resistance $[\mathrm{Wood}$ Units] & 10.2 \\
\hline Pulmonary Arteriolar Resistance & 8.3 \\
\hline $\begin{array}{c}\text { [Wood Units] } \\
\text { Pulmal }\end{array}$ & \\
\hline
\end{tabular}

Following manual setting of HR, Pra, PCWP, total pulmonary and arteriole resistances, $B S A$ and estimated right end-diastolic volume $(E D V)$, CARDIOSIM $^{\odot}$ software automatically adjusts the value of the resistance $R_{a p}$ to reproduce the measured mean $P A P$ value. Starting from these conditions the simulator reproduced the other measured parameters $(C O, C I$, $P A P$, stroke volume) and estimated the $E_{e s} / E_{a}$ ratio and the RC-time.

Oral combination therapy with a selective endothelin type A receptor antagonist (ambrisentan) and a phosphodiesterase type 5 inhibitor (tadalafil) was continued for six months following which further measurements were recorded and listed in Table 2. Both $E_{e s} / E_{a}$ and RC-time were estimated based on the above measurements using the cardiovascular numerical model in the absence of tricuspid regurgitation.

The results were compared with the previous simulations.

Table 2: Patient's Conditions Following Drug Treatment

\begin{tabular}{|c|c|}
\hline NYHA & II-III \\
\hline Heart Rate $(H R)[\mathrm{bpm}]$ & 72 \\
\hline Body Surface Area $(B S A)\left[\mathrm{m}^{2}\right]$ & 1.93 \\
\hline Right Atrial Pressure $(\mathrm{Pra})[\mathrm{mmHg}]$ & 7.0 \\
\hline $\begin{array}{c}\text { Mean Pulmonary Arterial Pressure }(P A P) \\
{[\mathrm{mmHg}]}\end{array}$ & 45.0 \\
\hline Mean $P C W P[\mathrm{mmHg}]$ & 12.0 \\
\hline Cardiac Output $(\mathrm{CO})\left[1 \cdot \mathrm{min}^{-1}\right]$ & 6.0 \\
\hline Cardiac Index $(C I)\left[\left(1 \cdot \mathrm{min}^{-1}\right) \cdot \mathrm{m}^{-2}\right]$ & 3.07 \\
\hline Total Pulmonary Resistance $[\mathrm{Wood}$ Units] & 7.5 \\
\hline $\begin{array}{c}\text { Pulmonary Arteriolar Resistance } \\
{[\text { Wood Units] }}\end{array}$ & 5.5 \\
\hline
\end{tabular}

\section{RESULTS}

Fig. 3 shows the screenshot produced with the software simulator starting from the baseline parameters reported in Table 1.

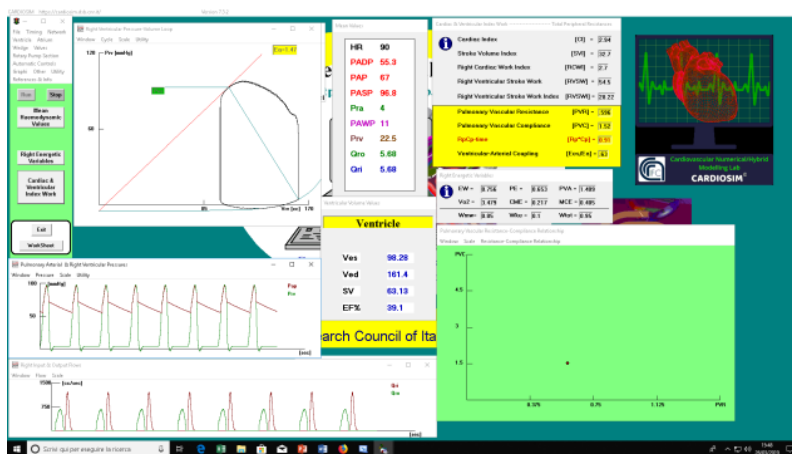

Figure 3: Baseline Conditions: CARDIOSIM ${ }^{\circ}$ Screenshot.

The right ventricular loop (upper left window), ESPVR, EDPVR and the pulmonary arterial elastance are reproduced in the $\mathrm{P}-\mathrm{V}$ plane under stationary conditions. The instantaneous ventricular (green waveform) and pulmonary pressures (red waveform) are plotted in the lower left window; both instantaneous right ventricular input/output (Qri/Qro red/green line) flow waveforms are plotted in the window below (Fig. 3).

The HR (90 bpm), the diastolic (PADP) and systolic $(P A S P)$ values for the pulmonary artery pressure, the mean pulmonary arterial pressure $(P A P)$, the mean right atrial pressure $(\mathrm{Pra})$, the mean pulmonary capillary wedge pressure $(P C W P)$, the mean right ventricular pressure $(P r v)$ and the mean right ventricular input/output flow (Qri/Qro) are reported in the upper central box. The lower right window shows the relationship between $P V R$ and $P V C$ (i.e. the RC-time or $\mathrm{RC}$ product). The pair of their values in the considered conditions is represented by the red point in the plane. 
The parameter values obtained in stationary conditions (Table 3) can be compared with the measured values (Table 1). Pulmonary vascular resistance is traditionally used to describe pulmonary hemodynamic characteristics. In Fig. $3 \mathrm{Ves}, \mathrm{Ved}$ and $\mathrm{SV}$ are the end-

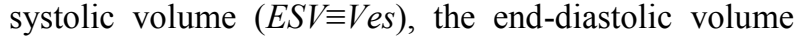
$(E D V \equiv V e d)$ and the stroke volume $(S V)$ respectively. $E W, P E$ and $P V A$ are the external work, the potential energy and the pressure volume area respectively (Sagawa 1988). A comparison between the oxygen consumption $\left(\mathrm{VO}_{2}\right)$ of the right ventricle (estimated with the software simulator) and that measured in the whole cardiac muscle is currently being considered by our group.

The new patient's conditions after treatment (Table 2) were reproduced by CARDIOSIM $^{\circ}$. The results are reported in Fig. 4 and Table 4.

Table 3: Parameters Obtained Using the Software Simulator (Baseline Conditions)

\begin{tabular}{|c|c|}
\hline Heart Rate $(H R)[\mathrm{bpm}]$ & 90 \\
\hline Body Surface Area $(B S A)\left[\mathrm{m}^{2}\right]$ & 1.93 \\
\hline Right Atrial Pressure $(\mathrm{Pra})[\mathrm{mmHg}]$ & 4.0 \\
\hline $\begin{array}{c}\text { Mean Pulmonary Arterial Pressure }(P A P) \\
{[\mathrm{mmHg}]}\end{array}$ & 66 \\
\hline Mean $P C W P[\mathrm{mmHg}]$ & 11.0 \\
\hline Cardiac Output $(C O)\left[1 \cdot \mathrm{min}^{-1}\right]$ & 5.68 \\
\hline Cardiac Index $(C I)\left[\left(1 \cdot \mathrm{min}^{-1}\right) \cdot \mathrm{m}^{-2}\right]$ & 2.94 \\
\hline $\begin{array}{l}\text { Total Pulmonary Resistance }(R p) \\
{\left[\mathrm{mmHg} \cdot \mathrm{ml}^{-1} \cdot \mathrm{sec}\right]}\end{array}$ & 0.596 \\
\hline $\begin{array}{c}\text { Pulmonary Vascular Compliance }(C p) \\
{\left[\mathrm{mmHg}^{-1} \cdot \mathrm{ml}\right]}\end{array}$ & 1.52 \\
\hline RC-time $(R p \cdot C p)[\mathrm{sec}]$ & 0.91 \\
\hline $\begin{array}{l}\text { Pulmonary Arterial Elastance }\left(E_{a}\right) \\
{\left[\mathrm{mmHg} \cdot \mathrm{ml}^{-1}\right]}\end{array}$ & 1.47 \\
\hline $\begin{array}{l}\text { Right Ventricular ESPVR Slope }\left(E_{e s}\right) \\
{\left[\mathrm{mmHg} \cdot \mathrm{ml}^{-1}\right]}\end{array}$ & 0.93 \\
\hline Ventricular Arterial Coupling $\left(E_{e s} / E_{a}\right)$ & 0.63 \\
\hline
\end{tabular}

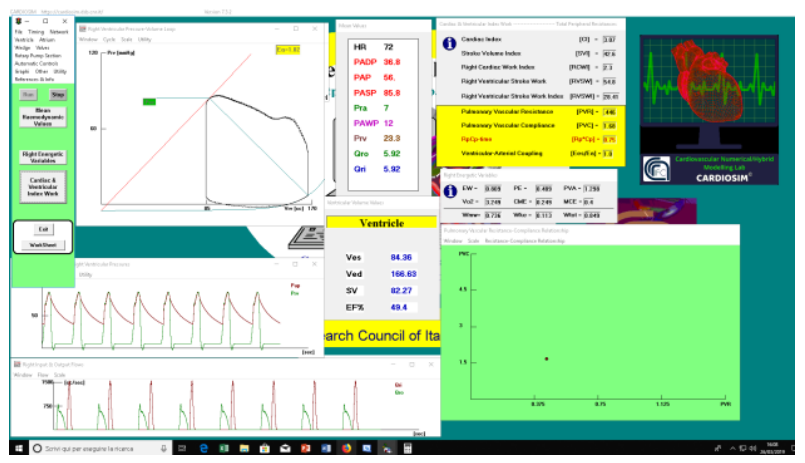

Figure 4: Patient Conditions After Six-Month Drug Treatment: CARDIOSIM ${ }^{\odot}$ Screenshot.

The effects induced by drug administration can be observed in the PVR-PVC plane where the red point shifts to the left and upward with respect to the previous position (see Figs. 3 and 4) confirming a decrease in pulmonary vascular resistance and an increase in pulmonary vascular compliance.

A comparison between the results listed in Table 3 (Fig. 3 ) with those obtained following drug treatment (Table 4 - Fig. 4) shows a decrease in pulmonary vascular resistance by about $25 \%$ (from 0.596 to 0.446 $\left.\mathrm{mmHg} \cdot \mathrm{ml}^{-1} \cdot \mathrm{sec}\right)$.

Simulation results show an increase in pulmonary vascular compliance by about $14 \%$ (from 1.52 to 1.68 $\left.\mathrm{mmHg}^{-1} \cdot \mathrm{ml}\right)$ following drug treatment.

Consequently, RC-time decreases from $0.91 \mathrm{sec}$ to 0.75 sec after a six-month drug treatment.

Table 4: Parameters Obtained Using the Software Simulator (After Six Months)

\begin{tabular}{|c|c|}
\hline Heart Rate $(H R)[\mathrm{bpm}]$ & 72 \\
\hline Body Surface Area $(B S A)\left[\mathrm{m}^{2}\right]$ & 1.93 \\
\hline Right Atrial Pressure $(\mathrm{Pra})[\mathrm{mmHg}]$ & 7.0 \\
\hline $\begin{array}{c}\text { Mean Pulmonary Arterial Pressure }(P A P) \\
{[\mathrm{mmHg}]}\end{array}$ & 56 \\
\hline Mean $P C W P[\mathrm{mmHg}]$ & 12.0 \\
\hline Cardiac Output $(\mathrm{CO})\left[1 \cdot \mathrm{min}^{-1}\right]$ & 5.92 \\
\hline Cardiac Index $(C I)\left[\left(1 \cdot \mathrm{min}^{-1}\right) \cdot \mathrm{m}^{-2}\right]$ & 3.07 \\
\hline $\begin{array}{l}\text { Total Pulmonary Resistance }(R p) \\
{\left[\mathrm{mmHg} \cdot \mathrm{ml}^{-1} \cdot \mathrm{sec}\right]}\end{array}$ & 0.446 \\
\hline $\begin{array}{c}\text { Pulmonary Vascular Compliance }(C p) \\
{\left[\mathrm{mmHg}^{-1} \cdot \mathrm{ml}\right]}\end{array}$ & 1.68 \\
\hline RC-time $(R p \cdot C p)[\mathrm{sec}]$ & 0.75 \\
\hline $\begin{array}{l}\text { Pulmonary Arterial Elastance }\left(E_{a}\right) \\
{\left[\left[\mathrm{mmHg} \cdot \mathrm{ml}^{-1}\right]\right.}\end{array}$ & 1.02 \\
\hline $\begin{array}{l}\text { Right Ventricular ESPVR Slope }\left(E_{e s}\right) \\
{\left[\left[\mathrm{mmHg} \cdot \mathrm{ml}^{-1}\right]\right.}\end{array}$ & 1.02 \\
\hline Ventricular Arterial Coupling $\left(E_{e s} / E_{a}\right)$ & 1.0 \\
\hline
\end{tabular}

The inverse coupling of $\mathrm{R}$ and $\mathrm{C}$ has direct and important hemodynamic consequences. A decrease in $\mathrm{R}$ is accompanied by a substantial increase in $\mathrm{C}$ in mild pulmonary hypertension $(\mathrm{PH})$ whereas the increase in $\mathrm{C}$ is negligible in severe $\mathrm{PH}$.

This may explain the clinical observation that patients with mild PH (moderately increased R) often show a greater hemodynamic improvement following treatment than patients with severe PH (strongly increased R), even if their $\mathrm{R}$ decreases by the same amount.

Finally, the simulated pharmacological treatment produced a $59 \%$ increase in ventricular arterial coupling $\left(E_{e s} / E_{a}\right)$; this effect is mainly attributable to approximately $70 \%$ reduction in $E_{a}$ (from 1.47 to 1.02 $\left.\mathrm{mmHg} \cdot \mathrm{ml}^{-1}\right)$. An $E_{e s} / E_{a}>1.0$, normally in the range of 1.5-2.0, allows for right ventricular flow output at minimal energy cost, and thus reflects optimal ventricular-arterial coupling (Sunagawa 1985, Vonk Noordegraaf 2013).

According to literature data $E_{e s} / E_{a}$ in patients with severe forms of pulmonary hypertension such as pulmonary arterial hypertension or chronic thromboembolic $\mathrm{PH}$, shows an adaptative increase in 
$E_{e s}$ with more or less preserved $E_{e s} / E_{a}$ ratio (Vonk Noordegraaf 2017).

\section{CONCLUSIONS}

The measurement of pulmonary vascular resistance $(P V R)$ is a convenient way to evaluate right ventricular afterload but it may not completely reflect its status because it does not consider the pulsatile component, which is significantly more important in the pulmonary circulation compared to the systemic circulation.

The effect of compliance seems to play a significant role in pulmonary arterial hypertension as addressed by the time constant (RC-time). A simulation approach may give ready information about the two components with a view to patient selection, treatment optimization and outcome prediction.

\section{REFERENCES}

Barst R.J., McGoon M., et al. 2004. Diagnosis and differential assessment of pulmonary arterial hypertension. J. Am. Coll. Cardiol., 43, S40-S47.

Guarracino F., Baldassarri R., et al. 2013. Ventriculoarterial decoupling in acutely hemodynamic states. Crit. Care, 17, 213.

Kuehne T., Yilmaz S., Steendijk P., et al. 2004. Magnetic Resonance Imaging Analysis of Right Ventricular Pressure-Volume Loops. In Vivo Validation and Clinical Application in Patients With Pulmonary Hypertension. Circulation, 110, 2010-2016.

Tello K., Dalmer A., Axmann J., et al. 2019. Reserve of Right Ventricular-Arterial Coupling in the Setting of Chronic Overload. Circulation: Heart Failure, 12(1), e005512.

Lankhaar J.W., Westerof N., Faes T.J.C., et al. 2006. Quantification of right ventricular afterload in patients with and without pulmonary hypertension. Am. J. Phsyol. Heart Circ. Physiol., 291, H1731H1737.

De Lazzari C., Darowski M., et al. 1998. The influence of left ventricle assist device and ventilatory support on energy-related cardiovascular variables. Med. Engi. \& Phys., 20(2), 83-91.

De Lazzari C. Stalteri D. 2011. CARDIOSIM ${ }^{\odot}$ cardiovascular software simulator. Italy: C.N.R. National Research Council, https://cardiosim.dsb.cnr.it/

De Lazzari C., Neglia D., et al. 2009. Computer simulation of coronary flow waveforms during caval occlusion. Meth. Infor. Med., 48(2), 113122.

De Lazzari C., D’Ambrosi A., Tufano F., et al. 2010. Cardiac resynchronization therapy: could a numerical simulator be a useful tool in order to predict the response of the biventricular pacemaker synchronization. Eur. Rev. Med. Pharmacol. Sci., 14(11), 969-978.
De Lazzari C., Capoccia M., Marconi S. 2019. How can LVAD support influence ventricular energetics parameters in advanced heart failure patients? A retrospective study. Computer Methods and Programs in Biomedicine, 172, 117-126.

De Lazzari C., Darowski M., Ferrari G., Pisanelli D.M., Tosti G 2006. Modelling in the study of interaction of Hemopump device and artificial ventilation. Computers in Biology and Medicine, 36 (11), 235-1251.

Fresiello L., Gu Y.J., et al. 2011. PUCA pump and IABP comparison: analysis of hemodynamic and energetic effects using a digital computer model of the circulation. Int. J. Artif. Organs, 34 (5), 442 455.

De Lazzari C., Darowski M., Ferrari G., et al. 2001. Ventricular energetics during mechanical ventilation and intraaortic balloon pumping Computer simulation. Journal of Medical Engineering \& Technology, 25 (3), 103-111.

Marconi S., Cappelli C., Capoccia M., et al. 2018. A New Numerical Model of the Intra-aortic Balloon Pump as a Tool for Clinical Simulation and Outcome Prediction. World Congress on Medical Physics and Biomedical Engineering 2018. IFMBE proceedings, Springer, 795-799.

Capoccia M., Marconi S., Singh A.A., et al. 2018. Simulation as a preoperative planning approach in advanced heart failure patients. A retrospective clinical analysis. BioMedical Engineering OnLine, 17:52.

De Lazzari C., Del Prete E., Genuini I., Fedele F. 2013. In silico study of the haemodynamic effects induced by mechanical ventilation and biventricular pacemaker. Computer Methods and Programs in Biomedicine, 110 (3), 519-527.

De Lazzari C., Genuini I., Quatember B., Fedele F. 2014. Mechanical ventilation and thoracic artificial lung assistance during mechanical circulatory support with PUCA pump: In silico study. Computer Methods and Programs in Biomedicine, 113 (2), 642-654.

De Lazzari C., Pirckhalava M. 2017. Cardiovascular and pulmonary artificial organs: educational training simulators. Rome: Consiglio Nazionale delle Ricerche (CNR) Press.

De Lazzari C., Darowski M., Wolski P. 2005. In vivo and simulation study of artificial ventilation effects on energetic variables in cardiosurgical patients. Meth. Infor. Med., 44(1), 98-105.

Sagawa K., Maughan L., Suga H. and Sunagawa K. 1988. Cardiac Contraction and the PressureVolume Relationships. Oxford University Press, New York.

Sunagawa K., Maughan W.L., Sagawa K. 1985. Optimal arterial resistance for the maximal stroke work studied in isolated canine left ventricle. Circ. Res. 56, 586-95. 
Vonk Noordegraaf A., Haddad F., Chin K.M., et al. 2013. Right heart adaptation to pulmonary arterial hypertension: physiology and pathobiology. J. Am. Coll. Cardiol. 62: Suppl., D22-D33.

Vonk Noordegraaf A., Westerhof B.E., Westerhof N. 2017. The relationship between the right ventricle and its load in pulmonary hypertension. J. Am. Coll. Cardiol. 69, 236-243. 